presented signs of glanders or reacted to mallein. There had been a case of equine glanders in the stables in March, 1904. Lastly, in Case ' 2 ulceration of the larynx was found, a lesion which, so far as I can ascertain from the literature on the subject I have at hand, is very rare. 'The lesion was quite recent and acute and was not apparently connected with the old healed tuberculous lesions found in the lungs.

Homerton, N.8.

\section{SYPHILIS OF THE THIRD GENERATION}

BY C. F. MARSHALL, M.D., B.So. VICT., F.R.C.S. ENG.,

LATE ASSISTANT SURGEON TO THE HOSPITAL FOR DISEASES OF THE SKIN, BLACKFRIARS.

THE hereditary transmission of syphilis to the third generation has recently been the subject of prolonged and careful investigation by several of the leading continent: syphilologists. In this article I propose to give a digest of the evidence on this important subject with the aid of an illustrative case. This case was kindly put at my disposa by $\mathrm{Mr}$. Albert Lucas of Birmingham and appears to be one of transmi-sion to the third generation, although there are obvious possible objections as in most of the cases published. The grandmother has the scars of multiple gummata about both knees. The mother at the age of 16 years had a gumma of the popliteal space and extensive destruction of the palate leading to constriction of the naso-charynx. She married at the aye of 19 years and had three children but no miscarriages. The first child, the case in question (third generation), has distinct saddle-nose deformity and frontal bosses but no other dystrophic stigma of hereditary syphilis. The second child died at the age of three years from "bronchitis"; the third child is said to be healthy. The father was not examined.

The possible flaws in the evidence in this case are : (1) acquired syphilis in the mother; (2) reinfection of the hereditarily spphilitic mother; (3) acquired syphilis in the father; and (4) the intervention of another syphilitic genitor. 1. In the atssence of obvious signs of hereditary syplilis in the mother it is impossible absolutely to exclude acquired syphilis but extensive or advanced tertiary syphilis at the age of 16 years is strongly in favour of the hereditary disease. 2. Re infection of a hereditarily syphilitic subject with acquired syphilis is known to occur and, according to Finger, the immunity conferred by the hereditary disease ceases at about the age of puberty. This re-infection of heredo-syphilis with acquired syphilis is called by Tarnowsky "binary syphilis," and according to him has a more disastrous effect on the offspring than the transmission of ordinary beredo-syphilis to the third generation. The evidence in the present case is in favour of pure transmission since the lesions in the child are exceedingly mild and also the mother has shown no evidence of acquired syphilis at any time. 3. Syphilis of the father cannot be excluded as he was not examined; but paternal heredity being apparently a well-established fact, in spite of the recent objections to the theory raised by Matzenhauer, it would be possible for a syphilitic father to beget a syphilitic child with a hereditarily syphilitic mother. 4. The same would apply to another syphilitic genitor in the case of the husband being free from syphilis. The possible intervention of another genitor is always a stumbling block in the elucidation of the problems of heredity, for although a child is obviously the offspring of his mother paternal parentage is usually incapable of scientific proof. Taking an all round view of the case, and considering that all three generations were under observarion by Mr. Lucas for some years, it appears to me that this case can be regarded as one of probable transmission of syphilis to the third generation.

I now propose to consider the evidence recently accumulated by the chief investigators of this subjrct. Professor Alfred Fournier, in his book on "L'Hérédité Syphilitique" 1891, remarks: "The hereditary transmission of syplilis to the second generation is a possible fact, rationally acceptable in principle but one the demonstration of which has not been irretutably e-tablished." Br second generation he means second heredity-i.e., third generation of the disease. Boeck has reported three cases observed at the clinic at Christiania. In the first case the grandmother was treated for secondary syphilis in 1854; the mother in 1860 for hereditary syphilis at the age of two years; the child in 1889, when four months old, for typical hereditary syphilis, with coryza, palmar and plantar syphilides, \&c. The mother at this time showed scars about the mouth and Hutchinson's teeth but had no sign of acquired syphilis. The father was examined but showed no sign of syphilis. The child in question was the second, the first being healthy. Also there was another healthy child begotten by another father a year before marriage. The objection in this case is, of course, the possibility of paternal heredity and of the first child after wedlock being procreated by the same father as that of the child born before marriage ; in other words, the syphilitic child might have been procreated by the father by paternal heredity, while the first two children were the offspring of another man. However, according to Fournier, cases occasionally occur where healthy children precede syphilitic ones. In Boeck's second case the grandmother was treated in 1873 for primary and secondary syphilis. After this she had one stillbirth and three living children. The eldest of these came to the clinic in 1897 with her own child suffering from hereditary syphilis. The mother had scars about the mouth but no other sign of hereditary syphilis. The father was not examined. In the third case the grandmotber had tertiary syphilis; the mother had scars about the mouth and Hutchinson's teeth; the child, aged five months, had hereditary syphilis. In this case a second child was born with the hereditary disease.

A report on the subject of transmission to the third generation was presented last year to the Société de Dermatologie et Syphilographie at Paris by Edmond Fournier. He discussed the two questions whether there is transmission of virulent syphilis to the third generation or only the dystrophic effects of hereditary ssphilis. He gives the following case in support of the transmission of virulent syphilis to the third generation. A man, aged 24 years, presented the scar of a tuberculous syphilide of the thigh which originated at the age of five years. He had also optic neuritis, diffuse retinitis, and ichthyosis. His father had marked signs of hereditary syphilis-signs of old keratitis, notched teeth, deafness, \&c. The grandmother had acquired syphilis contracted by suckling a syphilitic infant. She died from hemiplegia. In this case the subject had both dystrophic and virulent signs of hereditary syphilis. Fournier regards this case as free from any possible flaws. He has collected 116 cases published, 59 of which fulfil all the conditions required for transmission to the third generation. In these syphilis began in the grandparent and was transmitted to the children and grandchildren. He concludes (1) that there exists a syphilis of the third generation; (2) that this is rarely observed in practice because of the attenuating influences of time and treatment; and (3) that it manifests itself usually by dystrophic stigmata resembling those of hereditary syphilis, but that virulent symptoms may occur in about 14 per cent. of the cases.

Tarnowsky has made a comprehensive study of the subject based on prolonged observations during many years; his conclusions may be summed up as follows: 1. Syphilitic heredity manifests itself in three ways: by manifestations peculiar to hereditary syphilis, by dystrophic influence, and by an acquired immunity. 2. It is in the second generation of the syphilitic family that the hereditary influence of acquired syphilis declares itself with the greatest intensity in causing a considerable number of abortions, stillbirths, infants who succumb after several months of existence, and infants afflicted with signs of hereditary syphilis or different dystrophies. 3. Immunity of the second generation (Profeta's law) is generally only temporary. 4. The influence of syphilitic heredity diminishes sensibly in the third generation. This attenuation shows itself in the diminished number of abortions, stillbirths, and infants who die early; by the absence of phenomena in the third generation; and by the considerable diminuion in the number of dystrophies, as well as their qualitative attenuation. 5. Acquired syphilis of the first generation is not transmitited to the third in the form of the active manifestations of hereditary syphilis. Syphilitic heredity descending from the second to the third generation manifests itself exclusively by a dystrophic influence. In other words Tarnowsky does not support the transmission of what E. Fournier terms virulent syphilis to the third generation. 6. Transmission from the grandparents to the grandchildren by skipping a generation when the second generation have escaped s! philis has not been proved and 
it is doubtful whether it occurs. This view is also held by Alfred Fournier. 7. The dystrophic influence of acquired syphilis is not in proportion to the severity of the lesions; but the dystrophic influence of the second generation corresponds generally with the degree of the degeneration in the genitors. 8. When the second generation is not affected with the symptoms or dystrophies of hereditary syphilis it generally produces a healthy progeny. 9. Dystrophies of the second generation are not transmitted in the same form to the third generation. 10. Lesions of hereditary syphilis in the third generation (virulent adhesions of $\mathbf{E}$. Fournier) occur when there is new syphilitic infection of the second generation; to this Tarnowsky gives the name binary syphilis. This may also occur when a representative of the second generation marries a subject with acquired syphilis. 11. Binary syphilis exerts on the third generation a much more fatal influence than syphilis of the first on the second generation. There are a greater number of abortions, stillbirths, and early deaths, and the proportion of hereditary syphilitic phenomena and dystrophies is increased. Binary syphilis is one of the principal cauces of the rapid degeneration of the population of country districts. 12. The supposed progressive attenuation of syphilis in proportion to the spphilisation of the population is not supported by fact. 13. The fatal hereditary influence of acquired syphilis of the first generation manifests itself with the greatest intensity in the second generation, diminishes considerably in the third, and becomes absent in the fourth generation. Syphilis has an incomparably more fatal influence on the species and on society than on the individual.

The dystrophic stigmata which occur in both the second and third generations, according to E. Fournier, include a formidable list of affections. He mentions senile physingnomy, infantilism, cranial malformations, including asymmetry, synostoses, microcephalus, and hydrocephalus ; dental and maxillary dystrophies, including microłontism, displacements, dental erosions and malformations of the jaws hare-lip, cleft palate; ocular and aural dystrophies, including coloboma, strabismus, and malformations of the external ear, especially in form of satyr or fawn; spina bifida and scoliosis; dystrophies of the limbs, including partial giantism, polydactyly, syndactyly, congenital dislocation of the hip, and club-foot; cerebral dystrophies and anomailes of the spinal cord and deaf-mutism; cardiac and vascular anomalies, congenital cyanosis, Raynaud's disease; imperforate anus and hernia; ectopia vesicæ, epispadias uterine and vulvar anomalies, atrophy of the testis and hypospadias; ichthyosis, nævi, scleroderma, and dermoid cysts ; monstrosities, exomphalos, anencephalus, meningocele, \&c.; retarded intellectual development and irliocy; hæmorrhagic diathesis and paroxysmal hæmoglobinuria; epilepsy, hysteria, Little's disease, Friedreich's disease, \&c.-a truly imposing list. In some cases, no doubt. the dystrophies may have been due to other causes and accidentally associated with the syphilitic taint but the coincidences of these effects with syphilitic parentage are numerous enough to affirm a relation of cause and effect.

Transmission of syphilis to the third generation formed the subject of a discussion at the Paris Congress of Dermatology and Syphilis in 1900 and evirtence in favour thereof was given by Jullien and others. Barthelemy, at the Moscow Congress in 1897, had previously given an account of the history of hereditary syphilitic subjects, tending to show that the disease is transmitted to the third generation. He regarded syphilis, either by itself or by heredity, as one of the most active and rapid factors in causing degeneration of the human race.

Professor Finger at the Paris Congress mentioned the following objections which could be raised against transmission to the third generation: (1) the possibility of acquired syphilis in the second and third generations; (2) the somptoms should appear at birth, as late tertiary signs might be due to acquired syphilis in infancy; and (3) the dystrophies, if syphilitic in origin, should appear together with the usual signs of hereditary syphilis, but as a rule they occur separately.

Conclusion.-Such is the evidence up to the present time concerning the transmission of syphilis to the third generation. The question cannot be solved like a problem in Fuclid, and a broad and commonsense view mu-t be adopter, baser on the evidence as it stands, supplemented bo probabilities. Human beings cannot be kept under constant observation while breening, like animals, and therefore absolute elimination of all the possible flaws in the evidence is impossible. Also it is the good fortune of few of us to be able to follow up for three generations so many cases as Tarnowsky has succeeded in doing.

I think we must conclude: 1 . That the degenerative or dystrophic effects of syphilis are transmissible to the third generation and possibly further, only to die out with eventual sterility. 2. That, althongh difficult to prove, the transmission of virulent hereditary syphilis to the next generation is scientifically possitle ; the question depending chiefly on the two factors of time and treatment. We know that the signs of late hereditary syphilis may be delayed till the procreative age $; \mathbf{h}+$ nce a hereditarily syphilitic genitor in a virulent state might transmit the disease in a virulent form to the offspring. The reason why such cases are rare is the fact that a small proportion of cases marry while suffering from hereditary syphilis in a virulent form. At the time of marriage the direase is usually attenuated by time and also by treatment if this has been adequately administered. 3. That reinfection of a hereditarily syphilitic genitor increases the virulence of the disease and its fatal effects on the offepring (binary syphilis of Tarnowsky). 4. That the two chief obstacles to actual proof of transmission to the third generation are the possible reinfection of the second generation and the possible intervention of another syphilitic genitor.

Bibliography.--Barthelemy: Annales de Dermatolngie et de Syphiligraphie, October, 1897. Boeck: Berliner Klinische Wochenschrift, Sept. 12th, 1904. A. Fournier : L'Hérédité Syphilitique, 1891. E. Fournier: Annales de Dermatologie et de Svphiligraphie, July, 1904 ; Stigmates Dystrophiques de l'Heredo-Syphilis, 1898. Finger: Tarnou sky : La Syphilis, 1904.

Birmingham.

\section{RUPTURED INTERSTITIAL PREGNANCY; ABDOMINAL HYSTERECTOMY; DEATH.}

BY W. GIFFORD NASH, F.R.C.S. ENG.,

SENIOR SURGEON TO THE BEDFORD COUNTY HOSPITAL.

A woman, aged 30 years, the mother of one child 17 months old, ended her last period on Dec. 30th, 1903. On A pril 14th, 1904, about 8 P. M., she was suddenly seized with pain in the abdomen, faintness, and vomiting. At 2 A.M. on the 15th she sent for her medical attendant who gave her a hypodermic injection of morphine to relieve pain. Throughout the 15th she was in great pain, collapsed, and unable to retain any nourishment. Vomiting continued throughout the 16th. On the 17th I saw her in consultation on account of the frequent and uncontrollable vomiting. She was a big, strong, well-nourished young woman with an exceeningly blanched and pinched face, the aspect of abdominal disease being well marked. Her temperature was $100^{\circ} \mathrm{F}$. and the pulse was 140 . The latter was very weak and thready. She complained of great pain in the abdomen and of excessive thirst. She was restless and sweating. The abdomen was much distended and none of its contents could be felt. There was dulness in the flanks. Bimanual examination was unsatisfactory owing to the great abdominal distension but on vaginal examination the uterus felt crowded down and somewhat fixed. The os was patulous and the cervix was soft. The uterus itself was enlarged and around it was a softish fulness. There was no bæmorrhage from the os nor had there been any. I diagnosed "ruptured tubal gestation" and advised operation as soon as the necessary arrangements could be made. Consent was obtained and the same afternoon I opened the abdomen and found the lower part full of clotted and fluid blood. The intestines were much distended. The uterus was sought for and when brought into view a large rent was seen in the fundus, from which protruded membranes and clot. The foetus was found lying loose in the midst of coils of intestine. Owing to the apparent impossibility of closing the large tear in the uterus and stopping further hæmorrhage I decided to remove that organ by the supravaginal method. This was accordingly done, the blood and clots were cleared out, and the abdomen was closed. The patient stood the operation fairly well. Shock was combated by saline and nutrient rectial injections and strychnine subcutaneously. For about 24 hours progress was good, but then there was a return of vomiting with a rise of temperature, and death occurred at 2 A.M. on April 19th. 